\title{
USO DE SISTEMAS DINÂMICOS E SIMULAÇÃO COMPUTACIONAL NA MELHORIA DA PRODUTIVIDADE EM PROJETOS
}

\section{THE USE OF SYSTEM DYNAMICS AND COMPUTATIONAL SIMULATION IN ORDER TO IMPROVE PROJECT'S PRODUCTIVITY}

\author{
João Alberto Arantes do Amaral ${ }^{1}$; Ricardo Sbragio ${ }^{2}$ \\ ${ }^{1}$ Centro Universitário FIEO - UNIFIEO - Osasco - Brasil \\ jarantes@alum.mit.edu \\ ${ }^{2}$ Centro Universitário FIEO - UNIFIEO - Osasco - Brasil \\ rsbragio@umich.edu
}

\begin{abstract}
Resumo
Neste trabalho, são discutidos os fundamentos da Teoria dos Sistemas Dinâmicos e Simulação Computacional na gestão de projetos. Descreve-se o processo de representação da dinâmica de projetos por meio de relações de causalidade e ciclos de realimentação. Exemplifica-se o processo de criação de modelos computacionais usando-se estoques e fluxos. São apresentados os beneficios do uso dessas ferramentas em gestão de projetos.
\end{abstract}

Palavras-chave: Simulação Computacional, Sistemas Dinâmicos, Produtividade

\section{Introdução}

Gerentes de Projeto, constantemente pressionados por orçamentos restritos e prazos curtos, podem vir a tomar decisões precipitadas, empreendendo ações que, embora venham a trazer algum benefício no curto prazo, podem levar a inúmeros malefícios a médio e longo prazo (FORRESTER, 1971), (SENGE, 1990). A Teoria dos Sistemas Dinâmicos é uma ferramenta que pode ser usada em aplicações empresariais, para representar projetos complexos, auxiliando na análise das possíveis conseqüências das decisões gerenciais e reduzindo a probabilidade de fracassos (COOPER, 1993a, 1993b, 1993c), (AMARAL e SBRAGIO, 2004). Este artigo visa sistematizar os conceitos fundamentais dessa Teoria, exemplificar o seu uso em gestão de projetos e discutir seus benefícios. 


\section{Base teórica}

Projetos são sistemas dinâmicos, pois consistem de inúmeros componentes interdependentes e envolvem múltiplos processos de realimentação e relacionamentos não lineares (STERMAN, 1992). O gerente de projetos executa várias ações ao longo do projeto. Porém, algumas destas ações podem levar a resultados opostos aos desejados (AMARAL e SBRAGIO, 2004), (SENGE, 1990). A Teoria dos Sistemas Dinâmicos auxilia a entender esta dinâmica e a realizar análises qualitativa e quantitativa, por meio de ferramentas tais como as relações de causalidade e ciclos de realimentação.

\subsection{Relações de Causalidade e Ciclos de Realimentação}

As relações de causalidade relacionam duas variáveis de cada vez, desconsiderando a influência de outras variáveis sobre elas. Uma relação de causalidade é representada por uma seta ligando duas variáveis e um sinal positivo ou negativo (Figura 1). O sinal é positivo, caso o aumento (ou redução) da variável A provoque o aumento (ou redução) da variável B, e negativo, caso o aumento (ou redução) da variável A provoque a redução (ou aumento) da variável B (RICHARDSON, 1997), (STERMAN, 2001).

Figura 1 - Relações de causalidade positiva e negativa

Relação de causalidade positiva

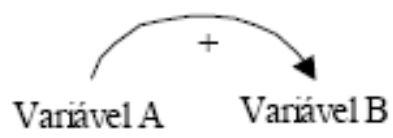

Relação de causalidade negativa

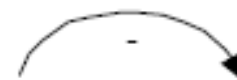

Variável A Variável B

Um ciclo de realimentação pode conter uma ou mais relações de causalidades. Um ciclo é positivo quando, ao se atribuir a uma de suas variáveis um acréscimo ou decréscimo e se percorrer o ciclo inteiro, ao final do percurso a variável sofre uma modificação no mesmo sentido da modificação inicial. Caso contrário, é negativo (Figura 2).

Figura 2 - Ciclos de realimentação positivo e negativo e seus efeitos
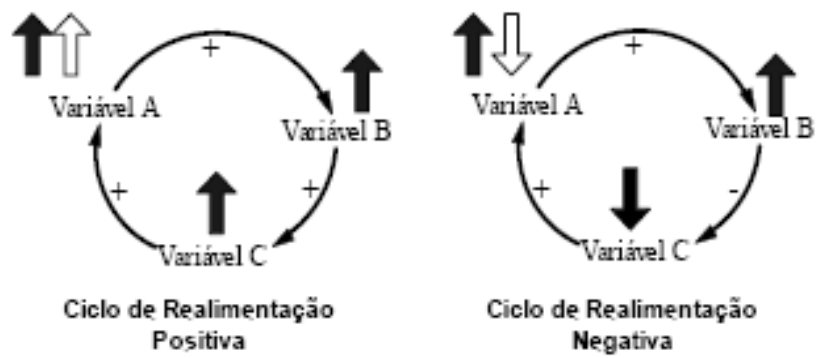


\subsection{Uso de ciclos de realimentação para representar a dinâmica de projetos}

A modelagem de um projeto deve, inicialmente, representar as relações de causalidade mais simples e, a partir daí, acrescentar novas relações, de modo a fechar os ciclos (HINES, 1999). Por exemplo, pode-se começar a modelagem representando os fatores que levam o gerente a exercer pressão sobre as equipes. $\mathrm{O}$ gerente visa garantir que o projeto termine dentro do orçamento, no prazo e com a qualidade definida. Ele está sujeito a pressões para realizar as tarefas no prazo. Quanto maior o número de tarefas a fazer, maior é a pressão sobre o gerente, que pressionará as equipes para que elas realizem as tarefas (Figura 3).

Figura 3 - Pressão do gerente de projetos sobre a equipe para que as tarefas sejam realizadas

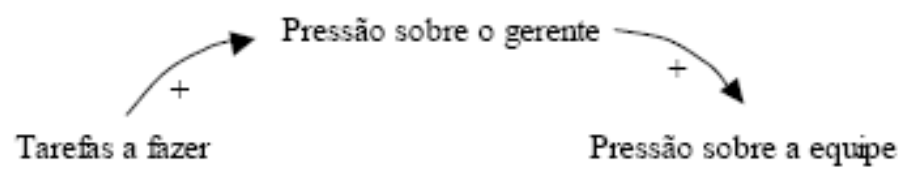

O aumento da pressão sobre a equipe implicará em um maior esforço de desenvolvimento, que pode ser conseguido por meio de um número maior de horas-extras. Isto levará, inicialmente, a um aumento na finalização de tarefas. Assim, o número de tarefas a fazer diminuirá (Figura 4), sendo este um exemplo de um ciclo de realimentação negativa.

A manutenção de uma pressão gerencial elevada pode levar ao surgimento de novos ciclos que irão interagir com o primeiro. Os bons resultados alcançados podem levar o gerente de projetos a prolongar a pressão sobre a equipe, levando os seus integrantes à fadiga. A fadiga leva à queda da qualidade nos produtos criados. A queda da qualidade leva ao aumento do retrabalho (COOPER, 1994), que, em última instância, levará a um aumento no número de tarefas a fazer, caracterizando uma realimentação positiva (Figura 5).

Figura 5 - O ciclo de criação de retrabalho

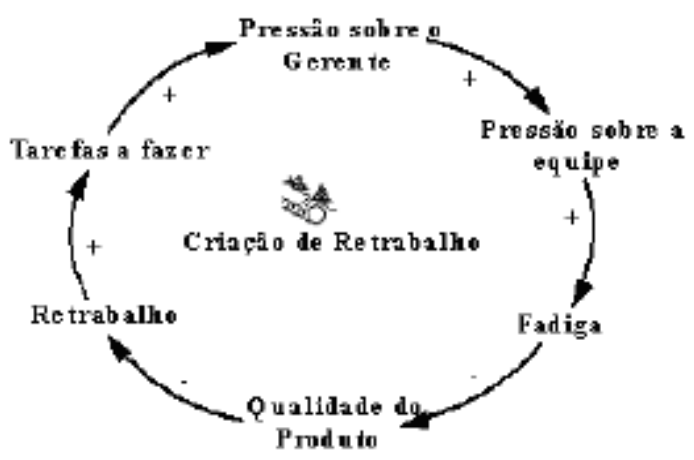

Fonte: (HINES, 1999) 
Os dois ciclos podem ser sobrepostos (Figura 6). O ciclo negativo é mais atuante no início do projeto, enquanto que o ciclo positivo tem um efeito maior em uma fase mais avançada do mesmo. Porém, para verificar se estes ciclos correspondem à realidade, devem-se criar modelos computacionais, usando-se as variáveis estoques e fluxos. Estoques são acumuladores, enquanto que os fluxos provocam variações dos estoques no tempo.

Figura 6 - Interação entre finalização de tarefas e criação de retrabalho

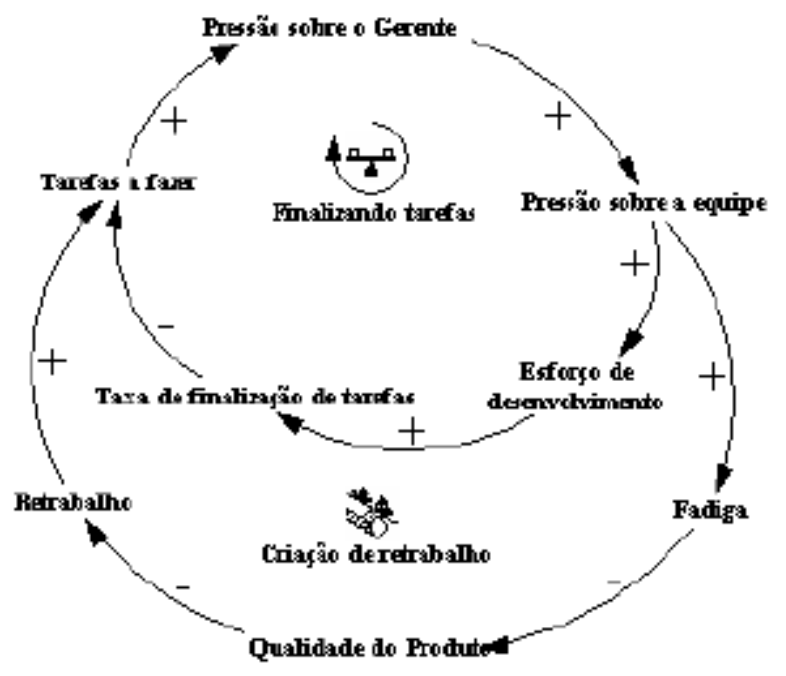

Fontes: (HINES, 1999), (STERMAN, 2001)

\section{Desenvolvimento do modelo computacional de um projeto}

O modelo computacional visa auxiliar o entendimento das dinâmicas envolvidas na finalização de tarefas e no retrabalho. Um projeto termina quando os trabalhos a fazer se tornam trabalhos finalizados (Figura 7). Um projeto pode ser representado inicialmente por dois estoques (trabalho a fazer e trabalho finalizado) e um fluxo (realização do trabalho).

Figura 7 - Estoques e fluxos

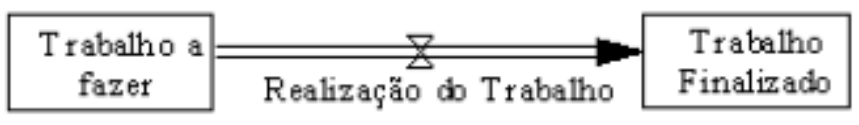

O fluxo de realização do trabalho é função do número de pessoas envolvidas, da produtividade e da qualidade. Porém, durante o projeto, ocorrem erros que geram retrabalho. $\mathrm{O}$ retrabalho não é descoberto imediatamente. Há uma demora entre a sua criação e a descoberta. 
Acrescentam-se, então, mais um estoque ao modelo ("Retrabalho não descoberto") e mais dois fluxos ("Geração de retrabalho" e "Descoberta de retrabalho", Figura 8). A qualidade influenciará na realização do trabalho e na geração de retrabalho. Mais qualidade implica em mais trabalhos finalizados e menos retrabalhos gerados.

Figura 8 - Ciclo do retrabalho em projetos

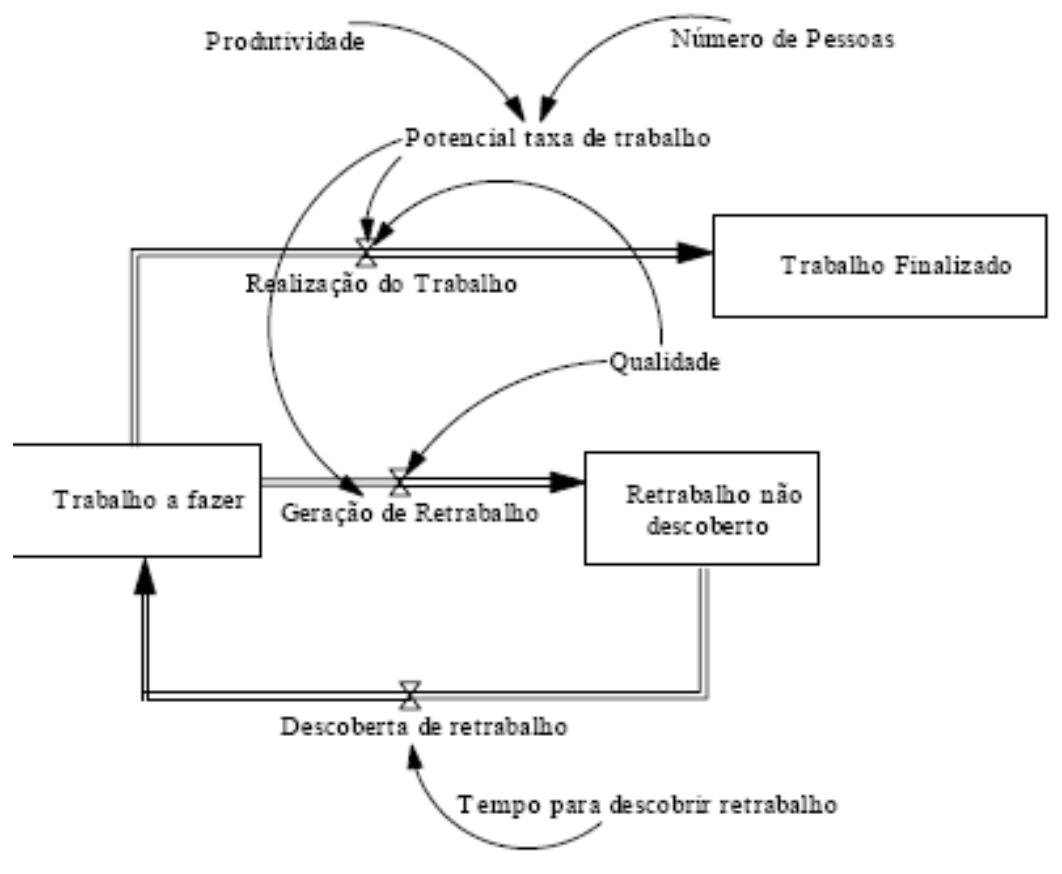

Fontes: (COOPER, 1993a, b e c), (LYNEIS, 2000)

Os efeitos da fadiga na qualidade e na produtividade devem ser acrescentados. A pressão gerencial aumentará o acúmulo de horas extras. Acrescenta-se, portanto, um estoque de horas extras e um fluxo (“Acumulando Horas Extras"). Embora aumentem a produtividade, as horas extras aumentarão também a fadiga, reduzindo a qualidade (Figura 9). 
Figura 9 - Efeito da pressão gerencial na produtividade e qualidade

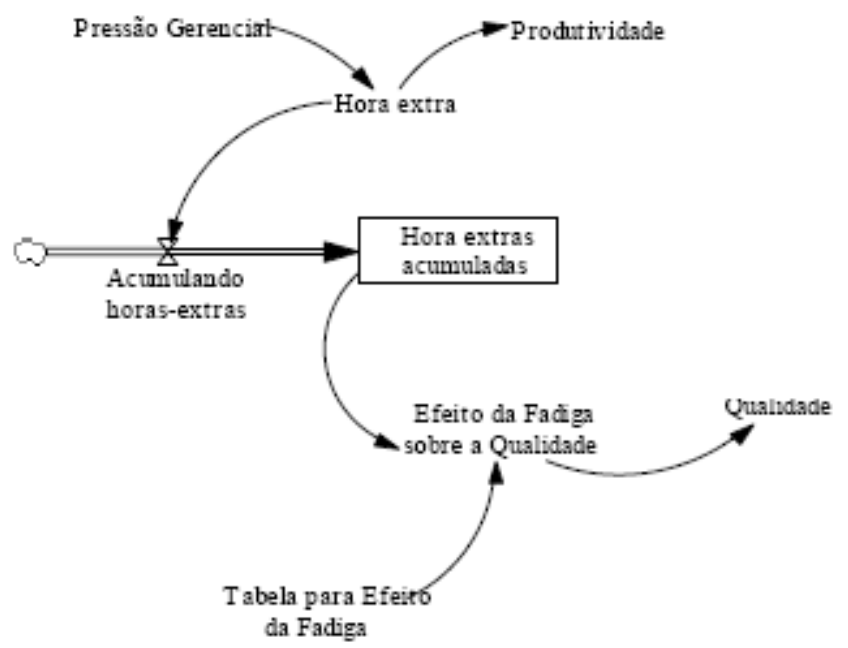

Fonte: LYNEIS, 2000

O modelo da Figura 9 traz as variáveis auxiliares "Efeito da Fadiga sobre a Qualidade" e "Tabela para Efeito da Fadiga" que visam introduzir um parâmetro qualitativo no modelo que é o efeito da fadiga reduzindo a qualidade. A Figura 10 apresenta o modelo final, que permitirá a análise dos ciclos de realimentação. O modelo computacional foi desenvolvido baseado no modelo expandido da Figura 10 em três passos, conforme será visto a seguir.

Figura 10 - Modelo expandido

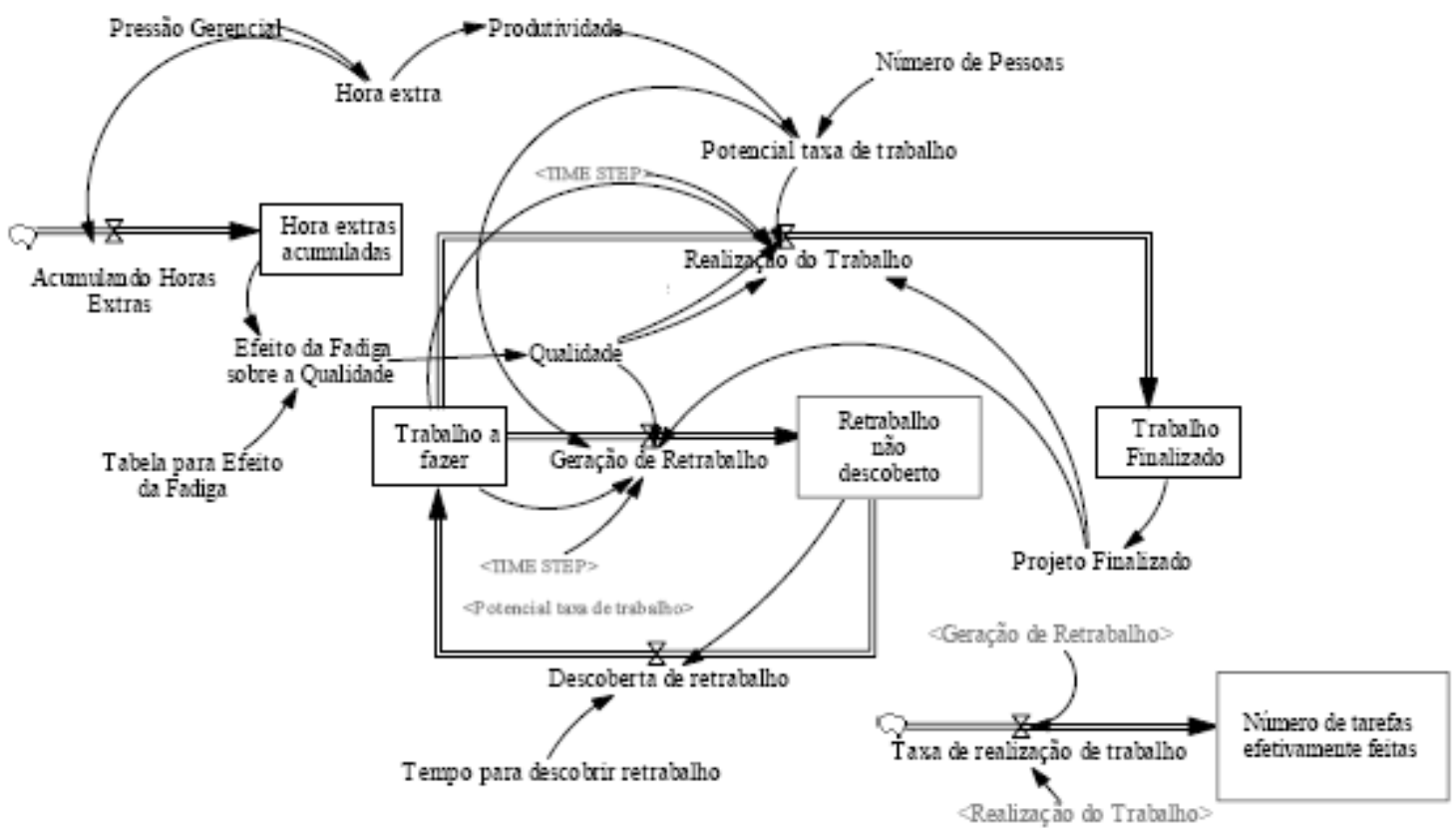

Fonte: LYNEIS, 2000 


\subsection{Simulação Computacional: $1^{\circ}$ Passo - Verificação das condições de equilíbrio}

Para realizar a simulação computacional, é necessário utilizar dados do projeto. Como exemplo, definiu-se um projeto com 100 trabalhos a fazer, 5 executores e uma produtividade igual a 1 Trabalho*Pessoa/Dia. Para a qualidade ideal (100\%), o projeto terminará em vinte dias, sem retrabalho. A simulação (Figura 11) confirma o resultado esperado, comprovando que as equações utilizadas cumprem as condições de equilíbrio.

Figura 11 - Finalização de trabalhos (quantidade de trabalhos e fazer e de retrabalho)

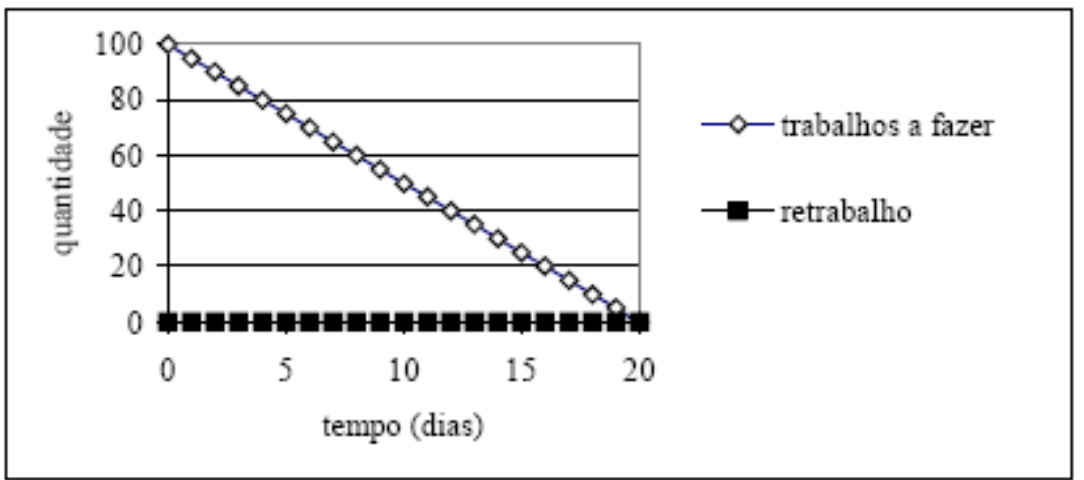

\subsection{Simulação Computacional: $2^{\circ}$ Passo - Verificação das dinâmicas fundamentais}

A dinâmica fundamental deste modelo é o ciclo do retrabalho, fortemente influenciado pela qualidade. Na simulação, define-se qualidade como a relação entre o número de trabalhos realizados corretamente dividido pelo número total de trabalhos realizados (LYNEIS, 2000). Arbitraram-se os seguintes valores para qualidade (Tabela 1):

Tabela 1 - Valores arbitrados para qualidade

\begin{tabular}{cc}
\hline Qualidade & Valor arbitrado \\
\hline Alta & 1 \\
Média & 0,75 \\
Baixa & 0,5 \\
\hline
\end{tabular}

A simulação demonstrou que, quanto maior a qualidade, mais rapidamente um projeto terminará (Figura 12) e que, à medida que a qualidade diminui, mais tempo leva para ser concluído, devido ao aumento do retrabalho (Figura 13).

Figura 12 - Efeito da qualidade no término do projeto (número de trabalhos a fazer) 


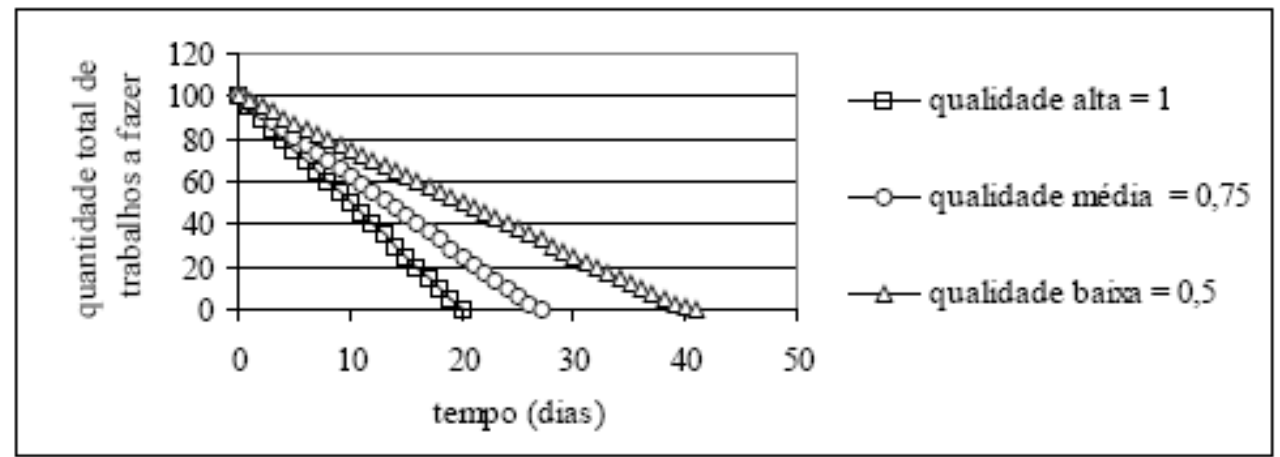

Figura 13 - Efeito da qualidade no retrabalho (número de retrabalhos)

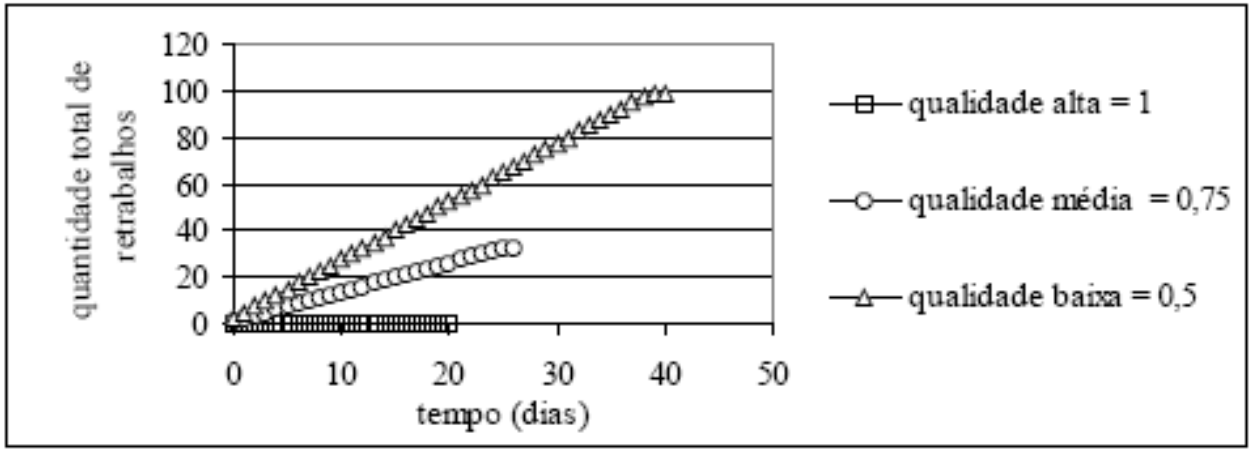

Observa-se também que o número de trabalhos efetivamente realizados (soma dos trabalhos feitos corretamente com os retrabalhos) aumenta à medida que a qualidade cai (Figura 14).

Figura 14 - Efeito da qualidade no número de trabalhos efetivamente realizados

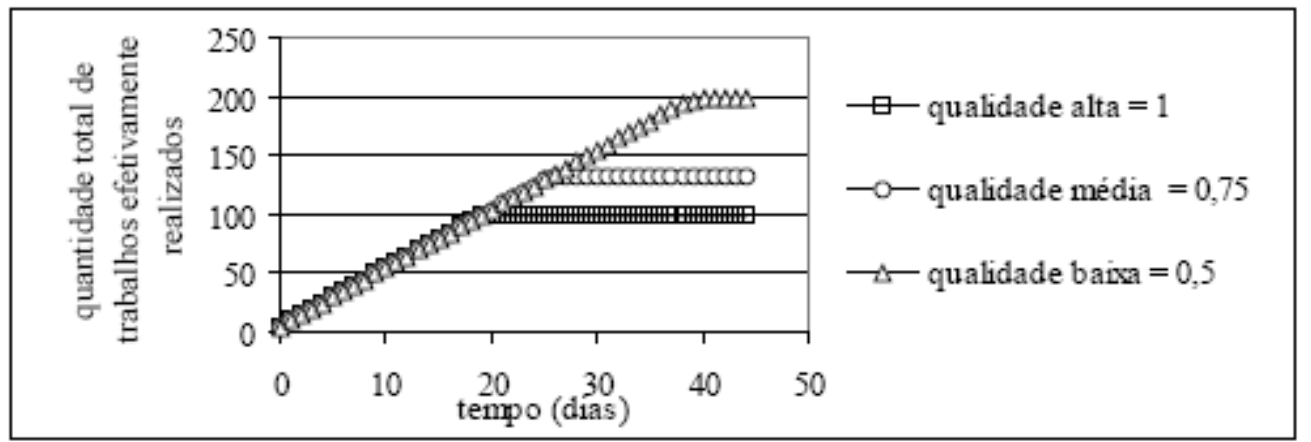

\subsection{Simulação Computacional: $3^{\circ}$ Passo - Análise do Modelo Integrado}

A análise do modelo integrado visa verificar o seu comportamento final. Supõe-se que a dinâmica de finalização de tarefas seja suplantada pela dinâmica de geração de retrabalho, caso a pressão gerencial seja mantida constante. O modelo computacional permite verificar essa suposição. 
Neste modelo, considerou-se que o número de horas extras realizadas é proporcional à pressão gerencial (Tabela 2), que a pressão gerencial aumenta a produtividade, proporcionalmente ao número de horas extras, e que a fadiga ocorre devido ao acúmulo no número de horas extras e afeta a qualidade.

Tabela 2 - Valores arbitrados para pressão gerencial

\begin{tabular}{cc}
\hline Pressão gerencial & Número de horas extras/dia \\
\hline Alta & 2 \\
Média & 1 \\
Baixa & 0 \\
\hline
\end{tabular}

O aumento da produtividade é proporcional ao número de horas extras trabalhadas. Assim, a produtividade de 1 Trabalho*Pessoa/Dia é acrescida de 1/8 a cada hora extra trabalhada. $\mathrm{O}$ aumento da pressão gerencial não gera apenas aumento da produtividade, mas também aumento da fadiga. A fadiga reduz a qualidade, conforme o número de horas extras acumuladas (Tabela 3). Assim, até 5 horas extras acumuladas, considera-se que a qualidade permanece inalterada. Entre 5 e 20 horas extras acumuladas, a qualidade cai pela metade (50\%) e acima de 20 horas extras acumuladas, a qualidade é igual a $25 \%$ do valor original.

Tabela 3 - Valores arbitrados para o efeito da fadiga sobre a qualidade

\begin{tabular}{cc}
\hline número de horas extras acumuladas & Efeito da fadiga sobre a qualidade \\
\hline Até 5 horas & $100 \%$ \\
entre 5 e 20 horas & $50 \%$ \\
Mais de 20 horas & $25 \%$ \\
\hline
\end{tabular}

O gráfico a seguir (Figura 15) mostra que o aumento da pressão gerencial leva, em curto prazo (durante os primeiros 4 dias para pressão alta e os primeiros 7 dias para pressão média), a um número maior de trabalhos finalizados.

Figura 15 - Efeito inicial do aumento da pressão gerencial nos trabalhos aprovados (qualidade alta $=1$ )

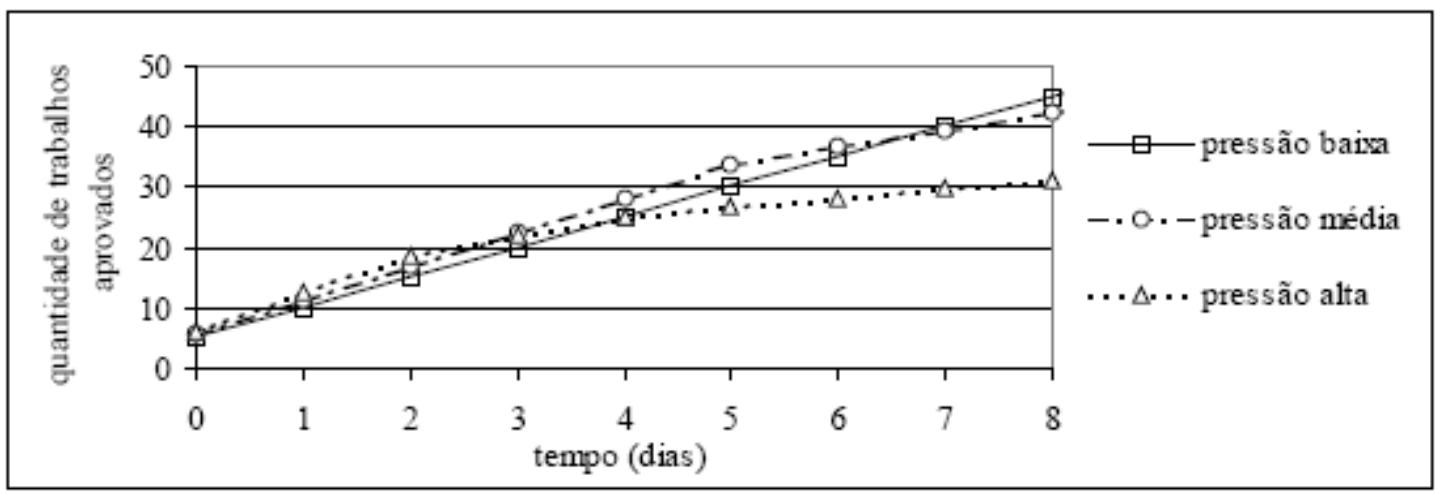


Porém, em longo prazo, esta tendência se inverte (Figura 16), devido ao efeito preponderante da fadiga sobre a qualidade.

Figura 16 - Efeito do aumento da pressão gerencial no projeto

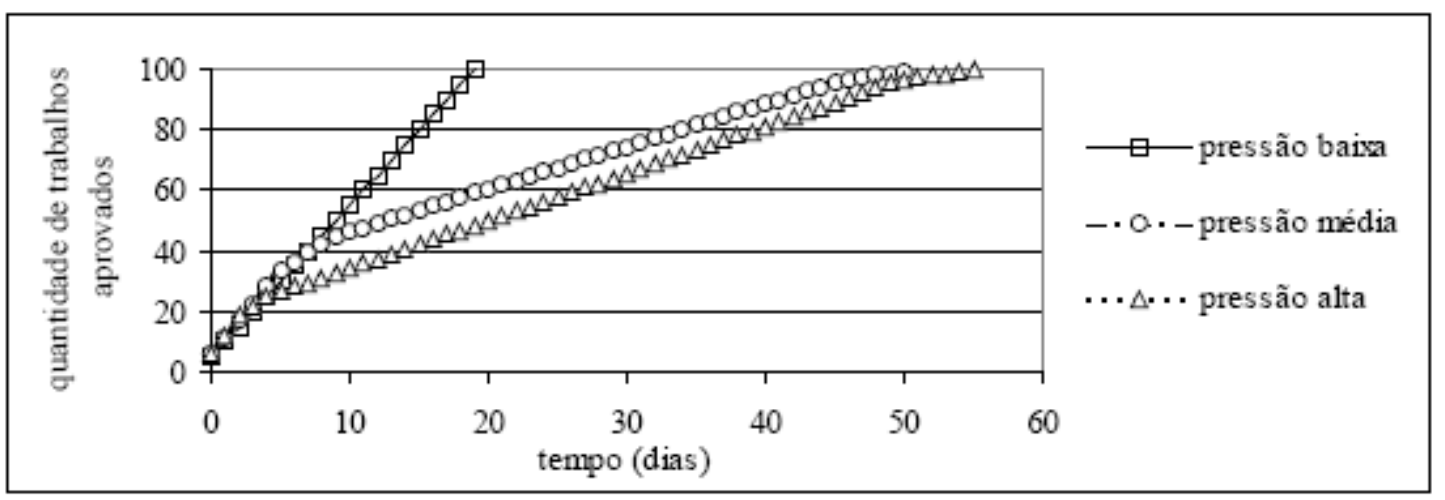

A simulação computacional permitiu concluir que o aumento da pressão gerencial leva a um aumento inicial na finalização dos trabalhos. Porém, à medida que a pressão permanece, a fadiga faz com que haja mais erros e, conseqüentemente, o retrabalho aumenta, levando a atrasos no projeto.

\section{Conclusão}

Este artigo apresentou o uso de Sistemas Dinâmicos e Simulação Computacional em gestão de projetos. Inicialmente, exemplificou-se como representar a dinâmica de projetos qualitativamente por meio de ciclos de realimentação. Estes ciclos têm por mérito tornar claro as possíveis conseqüências de ações gerenciais.

Os modelos computacionais, por sua vez, são usados para análises quantitativas. Criou-se um modelo computacional de um projeto, com o objetivo de proporcionar uma visão prática do processo envolvido na sua criação. Procurou-se abordar o tema sem entrar em detalhes computacionais e especificidades de ferramentas de desenvolvimento, a fim de proporcionar uma visão panorâmica de todo o processo envolvido.

A simulação computacional permite se obter os resultados de ações que, no mundo real, levariam semanas ou meses para ocorrer, além de possibilitar verificar a adequação de diversas estratégias gerenciais.

\section{Abstract}

This work presents the main aspects of System Dynamics Theory and Computational Simulation applied to project management. It describes the project's dynamics by the use of causal loops. The 
computational simulation is done using stock and flow concepts. It discusses the benefits of using these tools in project management field.

Keywords: Computational Simulation, System Dynamics, Productivity

\section{Referências}

AMARAL, J. A. A., SBRAGIO R. Modelos para Gestão de Projetos. São Paulo: Editora Scortecci,2004

COOPER, K.The Rework Cycle: Why Projects Are Mismanaged. PMNetwork. Project Management Institute, February, p.5-7, (1993a).

COOPER, K. The Rework Cycle: How it Really Works...and Reworks.... PMNetwork, Project Management Institute, February, p.25-28, (1993b).

COOPER, K. The Rework Cycle: Benchmarks for Project Manager. Project Management Journal, v. 24, p.17-21, (1993c).

COOPER, K. The \$2,000 Hour: How Managers Influence Project Performance Through the Rework Cycle. Project Management Journal, v. 25, p.11-24, 1994.

FORRESTER, J. Counterintuitive Behavior of Social Systems. Technology Review, v. 73, n.3, p.52-58, 1971.

HINES, J. The Standard Method, Massachusetts Institute of Technology, Applications of Systems Dynamics - Class Notes (não publicado), 1999.

LYNEIS, J. The Rework Cycle. Massachusetts Institute of Technology. Systems and Project Management -Class Notes ( não publicado), 2000.

RICHARDSON, G. P. Problems in Causal Loop Diagrams Revisited. System Dynamics Review. v. 13, n.3, May, p.247-252, 1997.

cross ${ }^{\text {ref }}$

SENGE , P. The Fifht Discipline: The Art and Practice of the Learning Organization. Boston: Doubleday, 1997

STERMAN, J. D. Business Dynamics: Systems Thinking and Modeling for a Complex World., Boston: McGraw-Hill, 2001.

\section{Dados completos do primeiro autor:}

Nome completo: João Alberto Arantes do Amaral

Filiação institucional: Centro Universitário FIEO- UNIFIEO

Função ou cargo ocupado: Professor

Endereço completo para correspondência (bairro, cidade, estado, país e CEP):

Rua Corinto 155, ap 124, Vila Indiana, São Paulo, CEP 05586-060

Telefones para contato: 011-3817-7505/ 011-72477854

e-mail:jarantes@alum.mit.edu

Recebido para publicação em: 23/12/2005

Aceito para publicação em: 13/02/2006 
